\title{
Symphysio-Fundal Height Measurement as a Means of Gestational Age Assessment in the Second Half of Pregnancy at the University of Ilorin Teaching Hospital, Nigeria
}

\author{
Folorunsho B. Adewale', Munir'deen A. ljaiya² \\ 'Department of Obs/Gyn, Federal Medical Centre, Bida, ${ }^{2}$ University of Ilorin Teaching Hospital, Maternity Wing
}

\begin{abstract}
Aims: Accurate determination of gestational age (GA) is an important part of obstetric care. The aim of this study is to determine the reliability of Symphsio-Fundal Height (SFH) measurement in assessing Gestational Age in the second half of pregnancy.

Methods: A total of 390 pregnant Nigerian women carrying uncomplicated singleton pregnancies between the gestational age of 20-40 weeks had SFH measurements done at the antenatal clinic, and ultrasonic biparietal diameter (BPD) and femur length (FL) determination at the fetal assessment unit, maternity wing of the University of Ilorin Teaching Hospital, Ilorin, Nigeria. The patients were followed up subsequently and managed till delivery. At delivery each baby was examined within the first 48 hours of life and gestational age at birth was assigned using the Ballard method.

Results: Of the 390 patients studied, SFH correctly assessed GA in $80 \%$ compared to $81.3 \%$ for BPD (P $=0.43), 82.1 \%$ for FL $(\mathrm{P}=0.41), 84.1 \%$ for BPD and FL $(\mathrm{p}=0.35)$. There is no significant difference in the sensitivity of SFH $93.1 \%$ and ultrasound $97.9 \%$. There is also no significant difference in the margin of error between the true gestational ages obtained by the two methods (SFH 15-41days Vs ultrasound 15-33days). Combined ultrasound parameters(BP \& FL),FL, BPD and SFH were progressively less closely correlated with the Ballard age of the fetus.

Conclusions: This study showed that accurate measurement of the SFH is a reliable method of gestational age assessment in the second half of pregnancy.
\end{abstract}

Keywords: Gestational age, second half of pregnancy, symphysio-fundal height

\section{INTRODUCTION}

Accurate determination of gestational age has always been an issue of concern to obstetricians since it greatly affects the management of antenatal patients. Many of the obstetric patients in the developing countries are uncertain of their last menstrual period, which constitutes a major problem to the attending health care provider. $^{1}$

Gestational age (GA) has traditionally been estimated from the date of the last menstrual period (LMP) and is the most reliable clinical estimator of actual gestational age. ${ }^{2}$ However the LMP is fraught with problems such as uncertainty of date. Approximately $10-45 \%$ of pregnant women cannot provide useful information about their LMP. $^{3}$ Other methods of determining gestational age include date of quickening, uterine size estimation by pelvic examination in early pregnancy, symphysio-fundal height estimation, amniotic fluid analysis, ultrasonic estimation and plain abdominal X-ray in late pregnancy. ${ }^{4-6}$

Opinions vary on the usefulness of the routine measurement of the SFH in the assessment of fetal age. Beazley and Underhill reported wide patient variation of their measurements and questioned the clinical relevance of this parameter. ${ }^{7}$ Belizan et al and Calvert et al, on the contrary, found the procedure to be simple inexpensive and reliable method of determining fetal age, and a useful screening test for intrauterine growth restriction. ${ }^{8,9}$ Egwuatu and Osefo also found that the formal measurement of sympysio-fundal height (SFH) using simple tape measure, is a fairly accurate method of estimating gestational age in the second half of pregnancy. ${ }^{1}$ In addition, its application in low resource countries, where sophisticated health technology is scarce is very useful.

\section{CORRESPONDENCE}

Dr. Munir'deen A. Ijaiya, DRH, FWACS

Department of Obstetrics and Gynecology

University of Ilorin Teaching Hospital,

Maternity wing, Ilorin, Nigeria.

Phone no: +2348033801565; +2348057068400

Email: munirijaiya@yahoo.com 
Gestational age assessment by clinical examination is helpful in the group of patients with an uncertain or unknown LMP. However, the addition of clinical information to a known LMP does tend to improve the precision of prediction of gestational age and delivery date. ${ }^{10}$

Marked discrepancies between the expected and estimated SFH would constitute an indication for further surveillance of the feto-placental unit in a well equipped Hospital. Most of the available data on symphysio-fundal height assessment relate to Caucasian women while little information is available from measurement in African women.

The aim of this study is to determine the reliability of Symphysio-fundal height measurement in assessing Gestational Age in the second half of pregnancy.

The specific objectives of the study are to compare:

i gestational age using LMP with symphysio-fundal height (SFH).

ii gestational age using LMP with biparietal and femur length (BPD\&FL).

iii gestational age using LMP with the Ballard score of the baby.

\section{METHODS}

An approval was obtained from University of llorin teaching hospital ethical / research committee for the study and informed consent was obtained from the patients. The study was conducted on 390 antenatal patients who met the inclusion criteria. The research took place at the department of Obstetrics \& Gynaecology of the university of Ilorin teaching hospital, Ilorin, Nigeria between May to December 2006. The inclusion criteria included pregnant women who were sure of their last menstrual period, singleton gestation, gestational age within 20- 40 weeks and with uncomplicated pregnancy. Exclusion criteria were uncertainty of last menstrual period, multiple gestations, suspected intrauterine growth restriction and presence of medical conditions or pregnancy complications such as diabetes mellitus, abnormal lie/ presentation hypertension and hydramnios.

Data obtained from the subjects include age, parity, LMP, educational status and occupation. All the patients recruited into the study had full physical examination. Parameters that were assessed include symphysio-fundal height, ultrasonic fetal biparietal diameter and femur length. Also each infant's age was assessed within 48 hours of delivery using the Ballard method. Babies' gender and birth weight were also recorded. A pre-tested questionnaire was administered.

Symphysio-fundal height was measured as described by Belizan et $a l .{ }^{8} \mathrm{~A}$ metric tape of non-elastic material was used to measure the distance from the uterine fundus (the beginning of the tape being placed there) to the superior border of the pubic symphysis. In order to avoid bias, measurements were made without prior knowledge of the patients' menstrual age. All measurements were recorded to the nearest centimeter. To avoid observer bias, the reverse side of the tape was used before turning the tape to the centimeter side to take the actual reading. Two measurements were taken and the average used as estimate of GA. Any estimated gestational age within two weeks of the true age obtained using the LMP was taken as correct.

All ultrasonic measurements were made with the SONOLINE SX Siemens sector scanner machine equipped with 3.5 $\mathrm{MHz}$ transducer. The BPD was measured as described by Silverman and Taylor. ${ }^{11}$ The fetal skull was displayed at the plane of the thalamus and the septum pelucidum, and the skull outline was ensured to be oval before taking the measurements. Measurements were made from the outer edge of the proximal skull to the inner edge of the distal skull (outer to inner). Femur length was measured by the method describe by $\mathrm{O}^{\prime}$ Brien et al. ${ }^{12}$ This involved moving the transducer transversely along the fetal trunk to the buttocks and then rotating the transducer to an angle of $30-45^{\circ}$ to the long axis of the vertebral column to ensure the ultrasound beam takes in the entire length of the femur, which is usually flexed. The actual femur length measured is that of the diaphysis from the proximal to the distal metaphysis excluding the femoral head and the distal epiphysis.

Patients were subsequently managed routinely till delivery. At delivery each baby was examined within 48 hours of birth and Gestational age at birth determined using the Ballard method. ${ }^{13}$ Combined external and neurological scores were used and single assessment was performed on each baby. The true gestational age at birth of each baby on the day of recruitment was deduced from the Ballard gestational age at birth. The number of weeks that have passed from the time the parameters -BPD, FL and SFH were taken was added to the time of delivery.

Data collected was analyzed using EPI-INFO software. The results were expressed as percentages and means with standard deviation. The observed difference was tested for significance using student $t$ - test and $p$ - values of $<0.05$ was taken as significant. The sensitivity and specificity of each of the methods were calculated using the LMP as the gold standard.

\section{RESULTS}

A total of 422 women were recruited for the study. Twenty of them did not deliver at UITH, Ilorin and were lost to follow up while 12 patients were excluded for other 
reasons, including three with stillbirth leaving 390 patients for analysis.

Table 1 shows the distribution of the patients according to their gestational age on the day of recruitment. One hundred and eighty five patients (47.4\%) were seen between twenty and thirty weeks, while the remaining 205 patients (52.6\%) were between thirty and forty weeks gestation. Only 20 patients $(5.1 \%)$ attended the antenatal booking clinic before the twentieth week of pregnancy.

Figure 1 shows the age distribution of the patients. The mean age was 29.5 years \pm 5SD (range 17-43years). Ten patients $(2.6 \%)$ were teenagers while 58 (14.8\%) were aged 35 years and above. Figure 2 shows the parity of the patients, the mean parity was 2.0 with a range of one to seven. One hundred and forty four were nulliparous and only eight were grandmultiparas. Table 2a shows the distribution of patients by occupation, One hundred and ninety one (49\%) were civil servants.

Table 1. Distribution of the patients according to gestational age (GA) at time of measurements

\begin{tabular}{lllll}
\hline $\begin{array}{l}\text { Gestational } \\
\text { age (weeks) }\end{array}$ & $\begin{array}{l}\text { Total No. of } \\
\text { patients }\end{array}$ & SFH & BPD & FL \\
\hline $20-24$ & 91 & 91 & 91 & 91 \\
$25-29$ & 94 & 94 & 94 & 94 \\
$30-34$ & 97 & 97 & 97 & 97 \\
$35-40$ & 108 & 108 & 108 & 108 \\
\hline Total & $\mathbf{3 9 0}$ & $\mathbf{3 9 0}$ & $\mathbf{3 9 0}$ & $\mathbf{3 9 0}$ \\
\hline
\end{tabular}

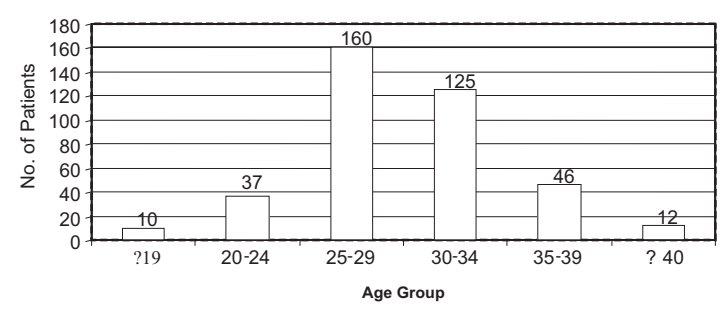

Figure 1. Distribution of patients by age

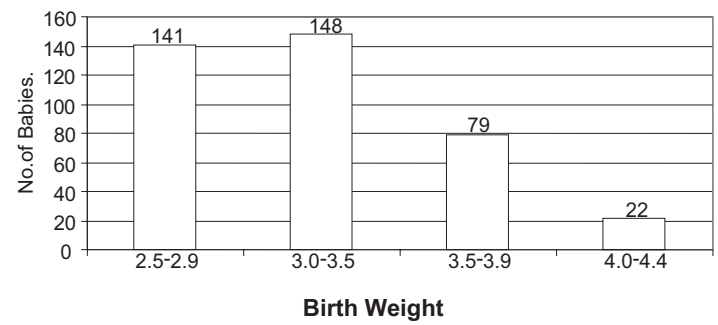

Figure 2. Distribution of patients by parity
Table 2. Socio-demographic characteristics of the patients

2a: Distribution by occupation

\begin{tabular}{lcc}
\hline Occupation & Frequency & Percentage \\
\hline Civil Servant & 191 & 49.0 \\
Hair Dressing & 69 & 17.8 \\
Fashion Design & 60 & 15.4 \\
Trading & 20 & 5.0 \\
Others & 50 & 12.8 \\
\hline Total & $\mathbf{3 9 0}$ & $\mathbf{1 0 0}$ \\
\hline
\end{tabular}

Table $2 \mathrm{~b}$ shows the distribution by marital status, 321 (82.3\%) were married while 13 (3.3\%) were divorced. Majority of the patients (89.8\%) had formal education.

\section{2b: Distribution by marital status}

\begin{tabular}{lcc}
\hline Marital status & Frequency & Percentage \\
\hline Married & 321 & 82.3 \\
Separated & 41 & 10.5 \\
Divorced & 13 & 3.3 \\
Other & 15 & 3.9 \\
\hline Total & $\mathbf{3 9 0}$ & $\mathbf{1 0 0}$ \\
\hline
\end{tabular}

2c: Distribution by educational status

\begin{tabular}{lcc}
\hline Level of education & Frequency & Percentage \\
\hline Primary & 26 & 6.6 \\
Secondary & 137 & 35.2 \\
Tertiary & 187 & 48.0 \\
Others & 40 & 10.2 \\
\hline Total & $\mathbf{3 9 0}$ & $\mathbf{1 0 0}$ \\
\hline
\end{tabular}

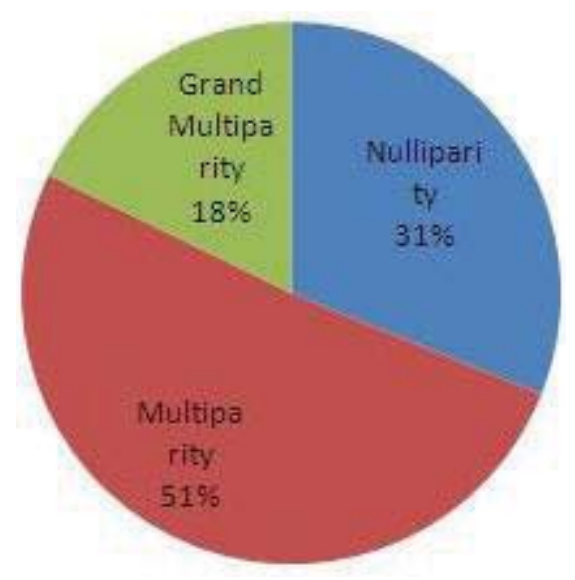

Figure 3. Distribution by Babies by Birth Weight

Two hundred and twenty nine patients (58.8\%) were Yoruba, while $105(26.8 \%)$ were Igbo. Figure 3 shows the babies' birth weight, the mean birth weight of the babies was $3.2 \mathrm{~kg} \pm 0.44 \mathrm{SD}$ with a range of $2.5-4.36 \mathrm{~kg}$. Two hundred and fourteen $(54.9 \%)$ of the babies were female while the remaining 176 (45.1\%) were male. 
Table 3. Comparison of symphysio-fundal height (SFH) with ultrasound biparietal diameter (BPD) and Femur Length (FL) measurements according to GA

\begin{tabular}{lllllll}
\hline $\begin{array}{l}\text { Gestational Age } \\
\text { (Weeks) }\end{array}$ & SHF & \multicolumn{5}{c}{ BPD \& FL } \\
\hline $20-25$ & Total & Correct $\mathbf{n}(\%)$ & Incorrect* $\mathbf{n}(\%)$ & Total & Correct $\mathbf{n}(\%)$ & Incorrect* $\mathbf{n}(\%)$ \\
$25-30$ & 91 & $74(81.3)$ & $17(18.7)$ & 91 & $78(85.7)$ & $13(14.3)$ \\
$30-35$ & 94 & $76(80.8)$ & $18(19.2)$ & 94 & $79(84.0)$ & $15(16.0)$ \\
$35-40$ & 97 & $77(79.3)$ & $20(20.0)$ & 97 & $81(83.5)$ & $16(16.5)$ \\
\hline
\end{tabular}

* An Error of $>2$ Weeks compared to Menstrual age.

Table 4. Summary of comparison of symphysio-fundal height (SFH) with ultrasound biparietal diameter (BPD) and femur length (FL) measurements

\begin{tabular}{|c|c|c|c|c|}
\hline \multirow[t]{2}{*}{ Method } & \multirow[t]{2}{*}{ No of measurements } & \multicolumn{2}{|c|}{ Gestational age assessment } & \multirow[t]{2}{*}{ P@ } \\
\hline & & Correct n (\%) & Incorrect* n (\%) & \\
\hline SFH & 390 & $312(80.0)$ & $78(20.0)$ & \\
\hline BPD & 390 & $317(81.3)$ & $73(18.7)$ & 0.43 \\
\hline $\mathrm{FL}$ & 390 & $320(82.1)$ & 70(17.9) & 0.41 \\
\hline BPD \& FL & 390 & $328(84.1)$ & 62 (15.9) & 0.35 \\
\hline
\end{tabular}

* An Error of >2 Weeks compared to Menstrual age. @Compared to SFH

Table 5. Sensitivity and specificity of SFH and ultrasound

\begin{tabular}{llll}
\hline Methods & Correct (+) & Incorrect (-) & Total \\
SFH & 312 & 0 & 312 \\
& (true & (false & \\
& positivecorrect) & negativecorrect) & \\
\hline \multirow{4}{*}{ positive } & 55 & 78 \\
& (true & \\
Total & 335 & negativeincorrect ) & \\
BPD \& FL & 328 (true & 55 & 390 \\
& positivecorrect) & neagtivecorrect) & \\
& 7 (false positive & 55 (etrue & 62 \\
& incorrect) & negativeincorrect) & \\
Total & 335 & 55 & 390 \\
\hline
\end{tabular}

There were altogether $780 \mathrm{SFH}$ measurements and 780 ultrasonic measurements carried out among the 390 women. Any estimated gestational age within two-weeks of the true age obtained using the LMP was taken as correct.

Table 3 shows the comparison of SFH with ultrasound (BPD \& FL) according to gestational age. With advancing pregnancy the degree of accuracy decreases in both methods. The percentage of accuracy reduces further after 36 weeks.

The mean gestational age at delivery by SFH was 39.58 weeks \pm 1.53 SD with a range of $33-43$ weeks. The mean GA by ultrasound (BPD \& FL) was 39.88 weeks \pm 1.41 SD with a range of 32.6-44 weeks. The margin of difference between GA using the LMP and GA estimated by SFH range from one day to five weeks plus six days, while that of ultrasound range from one day to four weeks plus five days. Eight ( $2 \%$ ) of the patients were delivered of post term infants while four (1\%) were delivered of preterm infants.

Table 4 presents the summary of the analysis in table 3 . Symphysio-fundal height measurement correctly assessed GA in $312(80 \%)$ of patients. This was not significantly different from BPD (81.3\%) and $\mathrm{FL}(82.1 \%)$ or $84.1 \%$ obtained by combination of the ultrasonic parameters (BPD \& FL). Combined use of the two ultrasound parameters did improve the accuracy of assessing gestational age or predicting the date of delivery, it is still not significantly better than using SFH alone. There is also no significant difference in the margin of error between the true gestational ages obtained by the two methods (SFH 1541days Vs ultrasound 15-33days).

Table 5 shows the sensitivity and specificity of SFH and ultrasound (BPD \& FL). The sensitivity and specificity of SFH measurement in this series is $312 / 335(93.1 \%)$ and $55 / 55$ $(100 \%)$ respectively while that of ultrasound is $328 / 335$ (97.9\%) and 55/55 (100\%) respectively.

Correlation ( $r$ ) analysis among the 390 patients revealed that gestational age determined by Ballard postnatal assessment correlated highly with that calculated from the date of last menstrual period using Naegele's rule ( $r=0.92$ $p<0.01$ ). Combined ultrasound parameters (BPD \& FL), $\mathrm{FL}, \mathrm{BPD}$, and SFH were progressively less closely correlated with the Ballard age of the fetus.

\section{DISCUSSION}

Assessment of gestational age is an important part of obstetric care. A diagnostic or therapeutic intervention in complicated pregnancies, particularly the decision to 
deliver the high-risk fetus, is often influenced by gestational age. ${ }^{13}$

This study showed that accurate measurement of the symphysio-fundal height is a reliable method of gestational age assessment in the second half of pregnancy. This is particularly significant in our environment where ultrasound is not readily available especially in our rural health centres. The sensitivity of SFH measurement in this series is $93.1 \%$, which compares favourably with $90 \%$ reported by Onah and Umezulike. ${ }^{14}$ The sensitivity of $97.9 \%$ for ultrasound in this study is similar to $97 \%$ reported earlier in this centre. ${ }^{15}$ There is no significant difference in the sensitivity of symphysio-fundal measurements and ultrasonic measurement (93.1\% Vs $97.9 \%$ ) in this series.

The accuracy of ultrasound just like that of SFH in assessing GA decreases as the gestational age advances. This was confirmed in the study as the percentage of accuracy decreases as the pregnancy advances. The margin of error by ultrasound between 20 and 27 weeks was \pm 15 days. This was similar to \pm 14 days reported by Sabbagha and Hughey. ${ }^{16}$ At a GA of $28-40$ weeks the variability increases to \pm 33 days, this is however higher than \pm 22 days reported by Hadlock et al. ${ }^{17}$ In this series, the variability of SFH increases from \pm 18 days between 20 and 27 weeks to \pm 41 days between 28 and 40 weeks. This compare favourably with report of other workers. ${ }^{1,14,18,19}$

Although menstrual age assessment is regarded as the gold standard in gestational age estimation, this study revealed a high degree of correlation and similarity in gestational age estimation between Ballard gestational age and menstrual age assessment.

This study showed that there is no significant difference between SFH and ultrasound parameters in assessing gestational age or predicting date of delivery when use in the second half of pregnancy. In addition, there is no significant difference in the margin of error between the true gestational ages obtained by the two methods. This is relevant in many developing countries including Nigeria where ultrasound is not readily available in peripheral/rural maternity health facilities. These findings are in keeping with the findings of other researchers in this field. . $^{1,8,9,19-22}$ The variability of ultrasonic parameters approaches that of SFH measurements in the second half of pregnancy in this study. However, this finding differs from that of Beazley and Underhill who reported wide patient variation of their measurements and questioned the clinical relevance of this parameter. ${ }^{7}$

In this study, 4(1\%) of the patients were delivered of preterm infants while $8(2 \%)$ were delivered of post term infants. This indicates that the risk of significantly overestimating gestational age is quite small. The two percent post term deliveries in this series compares favourably with $1 \%$ reported by Hertz et al but the incidence of $1 \%$ of preterm deliveries was lower than $18 \%$ reported in their series. ${ }^{2}$
In conclusion, this study showed that ultrasound has no significant advantage over SFH measurement in assessing gestational age in the second half of pregnancy. SFH measurement is reliable in gestational age assessment, and fetal growth monitoring. Hence, the wider use of SFH measurement for this purpose might reduce the cost of antenatal care without loss of quality of care. Not only may gestational age be accurately determined in normal pregnancy in patients that are unsure of their dates, but more importantly, marked discrepancies between the expected and estimated SFH would constitute an indication for further surveillance of the fetal-placental unit.

\section{REFERENCES}

1. Egwuatu VE, Osefo NJ. Symphysis - fundus height and abdominal circumference measurements: Fetal age relationship in Nigeria women. West Afr J Med.1988;7:77-82.

2. Hertz RH, Sokol RJ, Knoke JD, Rosen MG, Chik L, Hirsch VJ. Clinical estimation of gestational age: Rules for avoiding preterm delivery. Am J Obstet Gynecol.1978;131:395-402.

3. Geirsson RT, Busby-Earle RM. Certain dates may not provide a reliable estimate of gestational age. Br J Obset Gynaecol.1991;98: 108.

4. Bernstein HB, Weinstein M. Calculation of gestational age and estimated date of confinement. In: Current obstetrics and gynecologic diagnosis and treatment. $10^{\text {th }}$ ed. Decherney $\mathrm{AH}$, Nathan L, Goodwin TM, Laufer N, editors. New York:McGraw-Hill; 2007;192 p.

5. Stuart C, Christoph L. The abdominal examination. In: Obstetrics by Ten Teachers. 17th ed. Stuart C, Christoph L, editors. London :Edward Arnold;2000; p. 8-11.

6. Ogunsina JA, Soyebi KO, Ogunseyinde AO, Abudu OO. Multiple fetal parameters in the estimation of gestational age in Nigerian pregnant women. West African Journal of Ultrasound.2001; 2:1721.

7. Beazley JM, Underhill RA. Fallacy of the Fundal height. Br Med J. 1970;4:404-6.

8. Belizan JM, Vallar J, Nardin JC, Malamud J, de vicuna LS. Diagnosis of intrauterine growth retardation by a simple clinical method: Measurement of uterine height. Am J Obstet Gynecol.1978;131: 643-6.

9. Calvert JP, Crean EE, Newcombe RG, Pearson JF. Antenatal screening by measurement of symphysis - fundus height. Br med J.1982;285: 846-9.

10. Andersen HF, Johnson Jr TRB, Flora JD, Barclay ML. Gestation age assessment II: Prediction from combined clinical observations. Am J Obstet Gynecol.1981;140:770 - 4

11. Silverman R, Taylor KJW. Determination of biparietal diameter In: Taylor KJW, editor. Atlas of gray scale ultrasonography. London:Churchill Livingstone;1978.p.322-7. 
lijiaya et al. Symphysio-Fundal Height Measurement as a Means of Gestational Age Assessment in the Second Half of Pregnancy at the University of Ilorin...

12. O'Brien GD, Queennan JT., Campbell S. Assessment of gestational age in the second timester by real time ultrasound measurement of the femur length. Am J Obstet Gynecol.1981;139:540-5.

13. Ballard JL, Novak KK,Driver M. A simplified score for assessment of fetal maturity of newly born infants. J Pediatr.1979;95:769.

14. Onah HE, Umezulike AC. Symphysis-fundal height measurements: A comparison of three techniques amongst rural Nigerian Igbo women. Orient J Med.2001;13:52-6.

15. Ijaiya MA, Aboyeji AP, Braimoh KT, Abubakar D. The role of ultrasound in obstetrics. Nig J Med.2002;11(2):50-55.

16. Sabbagha RE, Hughey M. Standardization of sonar cephalometry and gestational age. Obstet Gynecol.1978; 52:405.

17. Hadlock FP, Harrists RB, Deter RL, Park SK. Fetal femur length as a predictor of menstrual age: Sonographically measured. Am J Rad $.1982 ; 138: 875-8$
18. Jimenez JM, Tyson JE, Reisch JS. Clinical measures of gestational age in normal pregnancies. Obset Gynecol.1983;61:438 - 43.

19. Okonofua FE, Ayangade SO, Chan RCM, O' Brien PMS. A prospective comparison of clinical and ultrasonic methods of predicting normal and abnormal fetal growth. Int J Obstet Gynecol.1986;24:447-551.

20. Wenner W, Young EB. Nonspecific date of last menstrual period: An indication of poor reproductive outcome. Am J Obstet Gynecol. 1981;120:1071-9.

21. Kuti O, Osinusi BO, Ojengbede OA. Assessment of gestational age in the third trimester of pregnancy: Comparison of symphysio fundal height measurement with ultrasonic methods. Trop J Obstet Gynaecol.2003;20:123-6.

22. Araoye MO. Subject selection. In: Research methodology with statistics for health and social sciences. USA:Nathadex Pub;2003. p.117-120. 